\title{
Formação de grupos e redes de intercâmbio em pesquisa educacional: dialogia e qualidade
}

\author{
Bernardete A. Gatti \\ Fundação Carlos Chagas, Departamento de Pesquisas Educacionais \\ Pontifícia Universidade Católica de São Paulo, Programa de Pós-Graduação em Psicologia da Educação
}

\section{Introdução}

O pesquisador não trabalha sozinho, nem produz sozinho. A intercomunicação com pares, o trabalho em equipe, as redes de trocas de idéias e disseminação de propostas e achados de investigação, os grupos de referência temática, constituem hoje uma condição essencial à realização de investigações científicas e ao avanço dos conhecimentos. Para os pesquisadores mais experientes, esse diálogo permanente com grupos de referência temática torna-se fundamental ao avanço crítico e criterioso em teorizações, em metodologias, em inferências. Para os menos experientes, ou iniciantes, é fundamental para sua formação, pois não se aprende a pesquisar, não se desenvolvem habilidades de investigador apenas lendo manuais. Essa aprendizagem processa-se por interlocuções, interfaces, participações fecundas em grupos de trabalho, em redes que se criam, na vivência e convivência com pesquisadores mais maduros.

O intercâmbio científico tem um poder formativo inestimável e se processa não só por congressos e reuniões científicas de diversas naturezas, mas também por vários mecanismos como estágios, profes- sores visitantes, desenvolvimento de projetos interinstitucionais, participações em redes de pesquisadores em temas correlatos, participação em grupos de pesquisa etc. Esse intercâmbio pode desenvolver-se tanto em nível regional, nacional ou internacional, via programas básicos das agências de fomento à pesquisa, ou via programas de intercâmbio da Coordenação de Aperfeiçoamento de Pessoal de Nível Superior e o Comitê Francês de Avaliação da Cooperação Universitária com o Brasil (CAPES/COFECUB) e com o Serviço Alemão de Intercâmbio Acadêmico (CAPES/DAAD), com o Conselho Britânico, a Fundação Ford, e a Fundação Fullbright, entre outros, e ainda por convênios bilaterais mantidos por algumas universidades com financiamento próprio. Hoje contamos com nucleações de pesquisadores que, criada a interlocução, mantêm contatos pessoais periódicos, com maior ou menor freqüência, dependendo das suas possibilidades e interesses, para discutir projetos, enfoques, realizar seminários e estudos diversos, como parte de sua vida acadêmica. Essas nucleações reúnem, em geral, pesquisadores de regiões próximas, em razão de suas condições de mobilidade. Além disso, a Internet vem propiciando essa interlocução em 
redes nacionais ou internacionais, embora isso, na avaliação de pesquisadores, não dispense os contatos mais diretos.

O desenvolvimento da pesquisa em educação beneficiou-se, em décadas passadas, de iniciativas de intercâmbio que criaram possibilidades para fomentar interlocuções e formar grupos de referência. Na década de 1980, especialmente, desenvolveu-se um esforço grande, com apoio de agências de fomento e das associações, para constituir bases para trocas entre pesquisadores em mesma temática, que até então não tinham condição, nem a cultura, de intercambiar.

Neste texto vamos tomar como foco a análise de um programa de intercâmbio desenvolvido com o objetivo explícito de contribuir para a implantação e consolidação de grupos de pesquisa em educação no país, durante a década de 1980, e que desempenhou papel importante para a articulação tanto entre instituições quanto entre pesquisadores trabalhando em subáreas específicas da pesquisa educacional.

\section{O Programa de Intercâmbio: 1981-1992}

A proposta nasceu no bojo de um projeto mais amplo, o Programa Integrado de Educação, que no início dos anos de 1980, sob os auspícios do Conselho Nacional de Desenvolvimento Científico e Tecnológico (CNPq), Financiadora de Estudos e Projetos (FINEP), Instituto Nacional de Estudos e Pesquisas Educacionais Anísio Teixeira (INEP) e da CAPES, visava integrar as ações de fomento das quatro agências na área da educação. Várias discussões e levantamento de situações foram feitos pelos comitês de representantes da área nesses órgãos, em interlocução com a Associação Nacional de Pós-Graduação e Pesquisa em Educação (ANPEd), recém-criada em 1978. Em fins de 1981, constatavase que a pesquisa educacional no país se desenvolvia de modo esparso em universidades e instituições autônomas, públicas ou privadas, com alguns núcleos diversamente desenvolvidos, em função de suas condições materiais e humanas e também em função da origem e da evolução de suas atividades. As dificul- dades materiais, pela distância entre os diversos centros, e a falta de tradição de comunicação científica na área da pesquisa em educação, que estava começando a tomar corpo, resultava no relativo isolamento desses pesquisadores, que deixavam de se beneficiar da contribuição e da crítica dos seus pares para e sobre o seu trabalho. Pareceu importante e de grande interesse para o desenvolvimento da investigação em educação que houvesse condições para incentivar a comunicação e a cooperação entre os pesquisadores nela envolvidos, o que poderia contribuir para o aperfeiçoamento qualitativo do trabalho resultante.

Foi, então, proposto pelos comitês e agências de fomento um programa de intercâmbio na área da pesquisa educacional, nos moldes do que já havia na área da saúde. Por esse programa, dotado de recursos específicos, abrir-se-ia o leque de contatos dos pesquisadores e das próprias instituições às quais pertenciam. Visava-se, em último termo, à melhoria da qualidade da pesquisa educacional no país, por meio do aperfeiçoamento dos profissionais envolvidos, da permuta de informações e da realização de trabalhos de pesquisa em cooperação. Isso se efetivaria através de uma sistemática de intercâmbio com o trabalho face a face de pesquisadores das várias instituições envolvidas, bem como pela assessoria a grupos emergentes por grupos mais solidamente estabelecidos na área. Pelos documentos ${ }^{1}$ da época vê-se que se esperava que o resultado desse intercâmbio deveria ser o aprimoramento na elaboração teórica das pesquisas, o aprimoramento e a diversificação do tratamento metodológico, e, ainda, a criação de condições para a realização de pesquisas comparadas ou de trabalhos conjuntos de pesquisa.

A primeira etapa desse Programa de Intercâmbio teve o caráter de um projeto piloto, com o qual se procurou, por um lado, estabelecer uma estrutura básica sobre a qual montar um sistema mais amplo de intercâmbio e, por outro, testar modos de ação

${ }^{1}$ Os documentos referidos ao longo do texto estão na Fundação Carlos Chagas, arquivados no dossiê Projeto de Intercâmbio. 
para atingir os objetivos pretendidos. No entanto, tinha-se claro que um programa como esse atingiria seu melhor resultado quando envolvesse a grande maioria das instituições em que se desenvolviam trabalhos de pesquisa educacional do país.

A escolha dos centros que integraram o grupo de entidades cooperantes na primeira etapa do programa, cujos representantes compuseram seu comitê de gerência, foi feita de modo a se ter uma composição diversificada quanto à localização geográfica e à "maturidade” em pesquisa educacional. Pretendeu-se, assim, mesmo com um grupo pequeno de instituições no início, conseguir a representatividade de várias regiões do país e de vários níveis de qualificação científica.

Nos dias 14 e 15 de dezembro de 1981 realizouse a primeira reunião com a participação de representantes de seis universidades convidadas a participar do programa - Universidade Federal do Mato Grosso (UFMT), Universidade Federal do Pará (UFPA), Universidade Federal do Rio Grande do Sul (UFRGS), Universidade Federal de Santa Catarina (UFSC), Universidade Federal do Ceará (UFC), Universidade Federal da Paraíba (UFPB) - e de um centro de pesquisas: a Fundação Carlos Chagas (FCC). As principais idéias a serem implementadas, resultantes dessa reunião, podem ser assim resumidas:

1. privilegiar contatos entre pesquisadores em torno de projetos efetivamente em execução nas várias instituições participantes, os quais deveriam ser tratados como material de trabalho, e não como tema de exposição (essa atividade recebeu a denominação de "estágio");

2. favorecer a oportunidade de prestação de assessoria de um centro a outro, na forma de seminário ou cooperação em pesquisa;

3. procurar promover a produção de relatório conjunto, ou de relatórios paralelos comparativos, sobre pesquisas ou aspectos de pesquisas comuns a dois ou mais centros;

4. definir temas comuns de maior interesse de todos os centros como objeto do intercâmbio no correr do primeiro ano de atividades do Programa;
5. estimular outros tipos de comunicação entre as instituições participantes, tais como troca de publicações, de relatórios ou artigos, ou de informes sobre pesquisas em andamento. Segundo as orientações traçadas na reunião de representantes dos centros participantes, elaborou-se o projeto que veio a ser aprovado pelo CNPq e pela Sub-Secretaria de Cooperação Econômica e Técnica Internacional (SUBIN), agências financiadoras dos primeiros eventos desse programa. O Departamento de Pesquisas Educacionais da FCC foi designado para coordenação do programa apenas por razões de agilidade burocrática, estando todos de comum acordo (FCC, 1981, p. 2).

Relativas a duas grandes áreas temáticas, definidas na reunião inicial em função das pesquisas efetivamente em andamento nas instituições participantes - educação no meio rural e ensino de $1^{\circ}$ grau em periferias urbanas -, as atividades concretas do programa foram iniciadas no segundo semestre de 1982. Durante esse semestre foram realizados quatro estágios e uma assessoria à UFMT. Cada estágio envolvia em geral dois pesquisadores de cada uma das instituições, e foram sediados nas universidades federais do Ceará e do Rio Grande do Sul, e na FCC. Em continuidade, em 1983, realizou-se o restante da programação dessa fase, ou seja, mais três estágios (nas universidades federais da Paraíba, do Mato Grosso e do Rio Grande do Sul) e duas assessoriais (às universidades federais da Paraíba e do Pará). Todos os participantes dessas atividades encaminhavam à coordenação do Programa de Intercâmbio relatórios individuais, e o coordenador local dos estágios, um relatório geral.

\section{Consolidação do Programa de Intercâmbio}

O Programa vai-se implementando e consolidase nas articulações da comunidade acadêmica mobilizada na busca de alternativas para a melhor qualificação da pesquisa em educação, o que, acreditava-se, 
Formação de grupos e redes de intercâmbio em pesquisa educacional: dialogia e qualidade

tinha como um de seus fatores fundamentais a formação e o desenvolvimento dos próprios pesquisadores.

Em dezembro de 1983 realizou-se uma reunião com os representantes das instituições envolvidas para avaliar os trabalhos desenvolvidos e organizar novo plano de trabalho do programa, já expandindo para novos participantes. Nessa nova etapa foram incluídas mais oito instituições: universidades federais do Paraná, de Pernambuco, da Bahia, Fluminense, do Amazonas, de Alagoas e de Goiás, e o Instituto de Estudos Avançados em Educação da Fundação Getúlio Vargas do Rio de Janeiro (IESAE-FGV). Vários aspectos foram discutidos na reunião de avaliação e programação. Consolidou-se a filosofia de que o formato "estágio" parecia ser o meio mais efetivo de realizar os intercâmbios. Avaliou-se que, na primeira etapa do Programa (1982-1983), alguns dos estágios foram realizados à semelhança de "seminários” ou de "encontros”, por causa de vários motivos, como a dificuldade de todos os participantes "se livrarem" de formas consagradas de contato entre pesquisadores e de "ousarem” inovar radicalmente. Ou ainda, a dificuldade de operacionalizar a realização de estágios de modo que atendam aos interesses manifestados por todos os centros participantes na reunião em que se criou o programa. Ainda assim, observou-se que o espírito do estágio ia se impondo; os encontros foram, em sua maioria, reuniões de trabalho e debate sobre projetos concretos de cada pesquisador, e não de exposição teórica sobre temas ou teorias. Na programação da continuidade do programa de intercâmbio, recomendou-se que fossem promovidos ou reforçados: a troca de referências bibliográficas entre os grupos participantes e o envio de resumos das pesquisas realizadas ou em realização nas instituições engajadas; encontros com os grupos envolvidos numa periodicidade tal que permitisse um maior espaço de reflexão sobre os projetos; estágios programados nas instituições integrantes de acordo com as características e necessidades de outros grupos de pesquisa; o aprofundamento de questões teórico-metodológicas, no sentido de avançar mais em alguns pontos comuns aos grupos de pesquisadores. Elaborou-se também documento para orientar as atividades dos estágios, no que se lê:

Entende-se por estágio, no programa de intercâmbio, a situação em que pesquisador(es) de um Centro responsável por ou participante(s) de uma pesquisa em andamento desloca(m)-se para outro Centro durante certo tempo e ali entra(m) em contato com outro(s) pesquisador(es) envolvido(s) em pesquisa relativa ao mesmo problema, ou realizada com a mesma metodologia, ou interessada numa mesma teoria, para a troca de experiências e de idéias em situação de trabalho. O que se pretende com esse tipo de ação é: a) que pesquisadores envolvidos em pesquisas análogas tenham contato pessoal direto e que esse contato se centre nos problemas concretos das pesquisas em que estão envolvidos; b) que a troca de informações, experiências e idéias realizadas em função de interesses comuns representem apoio e estímulo recíprocos para os pesquisadores e que esse contato direto tenha continuidade de outros modos, independentemente do programa; c) que, instalado esse intercâmbio, se desenvolva o interesse por outras formas de colaboração entre os pesquisadores e entre os Centros, tais como a realização de pesquisas comparativas ou de pesquisas em colaboração. (ANPEd, 1984,p. 3)

Nessa reunião de dezembro de 1983, a fim de montar o novo plano de trabalho para intercâmbios de grupos de pesquisa, as 15 instituições então participantes trouxeram por escrito informações sobre a sua instituição, o número de pesquisadores e seu grau de formação, o número de pesquisas concluídas nos últimos dois anos, o número e o tipo de publicações, o número de pesquisas em andamento com os respectivos temas de trabalho. A partir da exposição dos representantes, montou-se um quadro de interesses comuns para intercâmbio, cruzando as diferentes instituições e respectivos projetos. A partir desse quadro a coordenação do programa fez a compatibilização com as verbas disponíveis, posteriormente liberadas pelas agências financiadoras. Em decorrência, foram realizados em 1984 os seguintes estágios, envolvendo todas as instituições participantes conforme seus 
grupos de pesquisa: 1) para formação do professor de $1^{\text {a }}$ a $4^{\text {a }}$ série do $1^{\circ}$ grau; 2) sobre projetos de pesquisa cuja metodologia básica prendia-se à proposta de pesquisa-ação; 3) sobre projetos ligados à dinâmica da escolarização; 4) para discussão de projetos de pesquisa ligados à área de educação no meio rural e de questões relativas a problemas de educação e trabalho; 5) para discussão de projetos que trabalhavam com o conceito teórico de representação social; o grupo da Paraíba, inclusive, elaborou um documento teórico básico sobre fontes para o estudo de representação social, que serviu de pedra de toque para os trabalhos com os projetos específicos e a questão da construção teórica do referido conceito.

O mesmo procedimento - reunião para avaliação e programação coletiva - presidiu a organização dos estágios em 1985-1986. O programa passou a abranger 21 instituições (além das mencionadas, incorporaram-se as universidades federais do Ceará, do Rio Grande do Norte, da Paraíba, do Mato Grosso do Sul, além das universidades de Brasília, de São Paulo, e a Pontifícia Universidade Católica de São Paulo). A programação desse período foi delineada em reunião de representantes das instituições participantes e das agências de fomento, realizada na sede do CNPq em Recife. Propôs-se a realização de 14 estágios; sete deles foram financiados e realizados em seguida, cobrindo as áreas de: alfabetização; educação rural; política, planejamento e financiamento da educação; currículo; educação e trabalho; educação especial; ensino de $2^{\circ}$ grau. Ao todo, envolveram-se nesses estágios 131 pesquisadores, tendo sido discutidos e trabalhados 73 projetos. Finalmente, complementadas as verbas ao final de 1986 e durante o ano de 1987, levou-se a termo a realização de mais nove estágios: dois sobre ensino de $2^{\circ}$ grau (na FCC e na UFMG), dois em currículo (na UFPR e na Universidade Federal de Goiás - UFGO) e um nas áreas de: educação especial (na UFPB), alfabetização (na UFMG), política, planejamento e financiamento da educação (na Universidade Federal de Pernambuco - UFPE), ensino de ciências (na Universidade Federal do Rio de Janeiro - UFRJ) e educação popular (na UFRGS).
Como pode ser observado, nesse período conseguiuse a execução de mais dois estágios além dos programados.

\section{Novas direções}

Durante a reunião de coordenadores de programas de pós-graduação em educação, realizada na $10^{\mathrm{a}}$ Reunião Anual da ANPEd, em 1987, o Programa de Intercâmbio foi discutido quanto a seus benefícios e quanto a alguns problemas que se levantavam - como, por exemplo, a não inclusão ainda de todas as instituições onde houvesse mestrado, a necessidade também existente de se fazer reuniões apenas de pesquisadores experimentados para discutir questões de ponta, as formas de coordenação local dos estágios etc. Consolida-se então nova maneira de trabalhar no programa. Em documento da ANPEd, propunha-se:

a) extensão dos estágios a todos os Programas de Pós-Graduação; b) nova forma de programação, sendo necessário montar imediatamente o quadro de estágios pretendidos para o $2^{\circ}$ semestre de 1987 e $1^{\circ}$ semestre de 1988. Esta nova proposta pressupõe que: a) o representante da instituição deverá ser o Coordenador da Pós-Graduação ou alguém por ele designado; b) critérios de participação dos pesquisadores deverão ser definidos; c) o Programa deverá ser discutido pelos Coordenadores de Pós-Graduação e os professores de sua unidade, levando-se em conta os possíveis participantes dos estágios. É necessário que cada Coordenador envie à Coordenação Geral os nomes dos pesquisadores interessados em participar, assim como cópia de seus projetos de pesquisa. A Coordenação Geral montará a programação, enviando-a aos Coordenadores dos Mestrados para compatibilização. Retornando à Coordenação Geral, esta programação será encaminhada às agências financiadoras, para consolidação e alocação de verbas para os estágios. Cada Programa deverá se pronunciar pelo máximo de cinco estágios e justificar se deseja sediar um deles; d) deverá haver permuta de informações entre os Coordenadores dos Programas de Pós-Graduação e os Grupos de Trabalho da ANPEd, pois estes poderão indicar estagiários. (ANPEd, 1987, p. 5) 
Foi ressaltado, ainda, que o Programa de Intercâmbio, por sua natureza, deveria privilegiar pesquisadores desconhecidos e novos núcleos de pesquisas. Discutiu-se o fato de que não existiam condições para os pesquisadores mais experientes realizarem intercâmbios a partir de relatórios acabados ou semiacabados das pesquisas; que eles precisavam de discussões mais críticas, tanto para o início de novos projetos quanto em decorrência de trabalhos anteriores e de novas abordagens. Propôs-se a realização de um segundo tipo de estágio no Programa de Intercâmbio, que viesse a atender a essas necessidades.

Nessa etapa do programa realizaram-se os seguintes estágios: ensino de ciências, na USP; educação rural, um na UFCE e outro no IESAE-FGV; currículo, na PUC-SP; ensino de $2^{\circ}$ grau, na UFRN; formação de professores, na Universidade Federal da Bahia (UFBA); trabalho e educação, no IESAE-FGV; história da educação, na PUC-Rio; ensino superior, na UFRJ; e política e planejamento, na UFPE. Esses estágios foram realizados em articulação com os grupos de trabalho (GT) da ANPEd, alguns trazendo pesquisadores menos experientes para as discussões face a face com pesquisadores mais experientes outros reunindo só pesquisadores mais experientes, para discutir problemas de ponta. Esse procedimento deu um forte reforço a vários grupos de trabalho.

\section{As novas perspectivas delineadas no Programa de Intercâmbio}

Para caracterizar a fase do Programa de Intercâmbio descrita acima, ilustramos com o ocorrido em alguns dos estágios, o que permitirá observar as novas perspectivas que se desenvolveram em seu interior. Os estágios de educação rural, reunindo membros do GT Educação e Movimentos Sociais no Campo, propiciaram, no primeiro momento, a formulação coletiva de um programa de estudos voltado para questões de ponta na área de educação no meio rural, e, no segundo, seu detalhamento em seis projetos institucionais e sua integração numa proposta conjunta. O GT sobre currículo avançou análises acerca de: pesquisa-intervenção, conteúdo e método na pesquisa em currículo, movimentos contemporâneos de currículo, difusão de resultados de pesquisas na área, o problema docente na disciplina currículo e política de pesquisa em currículo. O grupo propôs o estudo da viabilização de um programa de pós-doutoramento na área, a ser discutido com a CAPES. O estágio de trabalho e educação reuniu a coordenação central do GT Trabalho e Educação e seus coordenadores regionais. Essa reunião centrou sua discussão na produção do grupo nos últimos anos, sua participação nas reuniões científicas e sua contribuição no debate para a área de educação. Discutiu-se a opção por um aprofundamento teórico e histórico da questão trabalho e educação, e também sobre um problema que se evidenciava: a apreensão prática da relação trabalho/ educação. Segundo relatório desse estágio, a avaliação do grupo era que essa relação vinha assumido um caráter bastante abstrato e mistificador nos trabalhos publicados e em alguns enfoques. Esforço deveria ser feito na busca de uma atitude mais crítica orientando as análises para os usos no âmbito educacional da relação trabalho/educação, questão importante sobretudo ante o momento em que se discutia o anteprojeto da Lei de Diretrizes e Bases da Educação Nacional (LDB). A reunião-estágio do GT Política de Ensino Superior discutiu, com base nos estudos e pesquisas desenvolvidos, pontos julgados importantes para o capítulo relativo ao ensino superior na nova lei: autonomia universitária, gestão democrática, normatização e supervisão, carreira docente, pós-graduação. Um documento foi elaborado e encaminhado a todos os membros do GT, para servir de base às próximas discussões e ao trabalho na ANPEd. Mais ainda: o conteúdo desse documento foi incorporado, praticamente na íntegra, ao projeto substitutivo da LDB, elaborado pelo deputado Jorge Hage, em junho de 1990. O estágio de história de educação propiciou a análise de temas relativos à história e à historiografia, bem como a realização de um balanço da atuação do GT na área: seu crescimento, sua articulação com outros grupos e instituições ligadas à pesquisa histórica, a elaboração de pesquisas geradoras de projetos de in- 
vestigação de alcance regional e nacional e problemas ligados à socialização das informações coletadas e produzidas. Os resultados da discussão foram reunidos em uma carta-circular distribuída aos demais membros do GT História da Educação da ANPEd. Foi discutida ainda a situação da pesquisa histórica nos programas de pós-graduação em educação, gerando-se um roteiro de texto, que seria desenvolvido por um dos membros do GT, para debates no encontro anual da associação. O estágio de política e planejamento educacionais, organizado com o Grupo de Trabalho Estado e Política Educacional, buscou levantar subsídios para trabalhos futuros, tomando como parâmetro os seguintes pontos: a concepção de Estado e as políticas públicas, a democratização do Estado em relação à educação, as bases da democratização da educação. Levantaram-se alguns tópicos específicos para estudo, e cada membro participante se responsabilizou por um tópico, que seria aprofundado por meio de um texto a ser discutido na próxima reunião do GT. Esses textos deveriam compor-se em um documento-síntese a ser amplamente divulgado. Nos demais estágios dessa fase discutiram-se projetos específicos de cada área de pesquisa, tendo havido também discussões mais gerais sobre a produção do conhecimento e a universidade, assim como o contexto da pesquisa educacional e sua especificidade.

A extensão dos estágios a todos os programas de pós-graduação e sua vinculação aos GTs da ANPEd, como se vê, deu nova feição aos trabalhos. Passam a ser consolidados como workshops e, após nova discussão na $11^{a}$ Reunião Anual da ANPEd, em 1988, a organização dos intercâmbios foi transferida definitivamente para os grupos de trabalho, que, apoiados pela direção da associação, passaram a propor e organizar os futuros encontros em função da própria evolução dos GTs e de suas necessidades, e a responder também pela solicitação de auxílio junto às agências financiadoras. Dados levantados junto ao CNPq mostram que em 1991 houve três workshops: Didática, Currículo, História da Educação; e em 1992, outros três: Educação Popular, Educação Especial,
Educação e Trabalho. Isso nos mostra uma continuidade do espírito do Programa de Intercâmbio, agora assumido por grupos de pesquisadores que tomavam a iniciativa de planejar e desenvolver seus encontros a partir de interesses específicos e de sua avaliação na participação dos grupos de trabalho da ANPEd. Em contrapartida, progressivamente decresceu o número de encontros desse tipo, até praticamente se extinguirem, seja pela emergência de outras oportunidades de discussão de projetos e perspectivas, seja, sobretudo, pelas dificuldades político-financeiras enfrentadas nesse período, associadas às mudanças nas políticas de fomento. Estamos nos primeiros anos de 1990.

\section{Impacto do Programa de Intercâmbio entre instituições de pesquisa educacional}

Pode-se ter uma idéia do impacto que esse programa gerou por meio dos relatórios dos estágios que os participantes e os coordenadores locais desses estágios faziam após cada ocorrência. Embora nem todos tenham enviado seus relatórios, a grande maioria o fez, e por meio de seus comentários e reações pessoais pode-se levantar alguns elementos que nos permitem fazer um balanço dos trabalhos realizados, pelo menos até o início de 1989.

A apreciação dos estágios pelos próprios participantes e coordenadores era bastante positiva, mas sempre apontando questões a serem melhoradas, dificuldades enfrentadas e apresentando propostas. Alguns relatórios detalham também questões metodológicas ou teóricas tratadas nos estágios.

Nas primeiras etapas do programa, todos os comentários são no sentido de que esse tipo de atividade estava faltando entre as instituições e os pesquisadores, e que ela vinha apresentando resultados interessantes para o enriquecimento dos vários grupos de pesquisa envolvidos, no que dizia respeito a suas preocupações com a prática da pesquisa. Percebe-se pelos depoimentos que esses encontros começaram a gerar relações recíprocas entre os grupos de pesquisa com preocupações afins, resultando em novos estágios de pesquisadores dessas instituições para 
Formação de grupos e redes de intercâmbio em pesquisa educacional: dialogia e qualidade

aprofundarem sua cooperação, realizados com outros meios. Várias dessas iniciativas são apontadas, e por aí pode-se ver que um dos objetivos do programa começava a se realizar. Nota-se que se desenvolvia o hábito de intercâmbio, discussão e enfrentamento de análises críticas, face a face. Observam-se desdobramentos inclusive com pesquisadores levando suas instituições a dedicar recursos também a essa forma de trabalho com outros docentes pesquisadores. Vários estágios incorporaram a participação de pesquisadores cuja viagem e estada foram custeadas pela sua própria instituição, e não pelo programa, evidenciando empenho das instituições em ampliar as possibilidades de seus docentes-pesquisadores na participação desses estágios. Um dos efeitos apreciáveis apontado foi o acesso a bibliografias específicas para pesquisadores cujas universidades não tinham acervos atualizados, bem como a trabalhos ainda não publicados, e a descoberta de fontes alternativas de informação e de obtenção de dados e informações, com o estabelecimento de um fluxo de trocas. Evidentemente, não foi esse programa que criou o conceito de intercâmbio entre pesquisadores, nem as instituições envolvidas eram jejunas em contatos e colaboração com outras instituições da área. Contudo, talvez o momento em que o programa foi ativado e a diversidade de experiências das instituições participantes nas primeiras etapas de sua execução fez com que fosse encarado com muito entusiasmo, patente nos relatórios. O entusiasmo aparece também por envolver instituições cujos pesquisadores tinham até então poucas oportunidades de expandir seus contatos, como os da UFMT, Universidade Federal do Amazonas (UFAM), UFPA, Universidade Federal de Alagoas (UFAL), dentre outras. Ainda, grande parte da explicação sobre as avaliações serem tão positivas talvez seja em virtude de que, aparentemente, era a primeira vez que explicitamente se destinavam recursos específicos para atividades de intercâmbio na área da pesquisa em educação, de modo sistemático e planejado pelos envolvidos. Costumeiramente, ofereciase financiamento para a realização de pesquisas ou, em nível de intercâmbio, para a realização de seminá- rios, congressos ou outros tipos de encontros e reuniões: em ambos os casos geram-se produtos palpáveis - na forma de relatórios de pesquisa ou na forma de anais - que concretizam, perante as agências financiadoras, o resultado da atividade financiada. No caso do Programa de Intercâmbio, pela primeira vez acenou-se com a possibilidade de haver recursos para facilitar o contato pessoal entre pesquisadores pertencentes a instituições que desenvolviam ou começavam a desenvolver pesquisa educacional, atividade esta que não resultava necessariamente em nenhum produto concreto, mas apenas em troca de idéias e experiências, lições mútuas, resolução de dúvidas, e no inevitável estímulo recíproco que nasce por saber-se que as dúvidas, as vacilações, as alegrias, os obstáculos, as compensações e as decepções que se encontram no trabalho de pesquisa são comuns aos colegas que fazem pesquisa em Cuiabá, na Paraíba, no Rio Grande do Sul, em São Paulo, no Rio de Janeiro ou em outros locais. Essa injeção diferente de recursos na área da pesquisa educacional, representando mais verba para uma atividade importante e nunca satisfatoriamente apoiada, e, simultaneamente, significando confiança no trabalho dos docentes pesquisadores, uma vez que não havia um produto palpável a ser exigido de imediato como prova física do uso dos recursos, foi, sem dúvida, muito importante. Significava um investimento a médio e longo prazo, coisa rara nas perspectivas de nossas instituições.

Pelo conteúdo dos relatórios nota-se, também, que em alguns poucos casos a organização e participação nos estágios não foi tão satisfatória. Embora se tenha elaborado um documento básico sobre suas características, houve casos em que a representação na instituição não divulgou os objetivos com clareza, ou não fez uma seleção adequada dos participantes locais em função da temática. Isso propiciou algumas oscilações nas participações, embora devamos reconhecer, pelos dados, que essas oscilações não prejudicaram os trabalhos, uma vez que a maior parte dos participantes assimilara a forma básica de trabalho proposta, e os relatórios mostram sobretudo a positividade do encontros face a face, em pequenos grupos. 
A expansão do Programa de Intercâmbio e sua posterior vinculação definitiva aos grupos de trabalho da ANPEd trouxeram avaliações, tanto de participantes quanto de coordenadores locais dos estágios, que refletem o que traduzimos como um amadurecimento de perspectivas. Não faltam exemplos disso nos relatórios disponíveis.

O impacto desse Programa de Intercâmbio não pode ser menosprezado. Nota-se no tempo a evolução de suas formas de organização, e, para além de sua ampliação em abrangência, uma melhor qualificação dos trabalhos desenvolvidos nos estágios, com reflexos tanto para os projetos de pesquisa como para as perspectivas de trabalho e investigação em várias subáreas da pesquisa educacional. A autonomia assumida por diversos grupos de trabalho da ANPEd na organização de seus estágios e a organização dos workshops dos últimos anos revela um novo patamar para a área, quer quanto à sua autonomia de trabalho, quer quanto ao aprofundamento de questões relevantes e específicas a cada temática e a metodologias. O próprio desenvolvimento e consolidação de alguns GTs da ANPEd estão associados a esse programa, que propiciou encontros, seminários, estágios, com financiamento garantido para participação dos pesquisadores, formando grupos e algumas redes de referência em várias das subáreas da pesquisa no campo da educação. Dos primeiros encontros à expansão, verifica-se que os participantes nesses estágios se consolidaram como pesquisadores-chave em suas subáreas, por suas pesquisas, trabalhos e publicações, bem como por seu papel na formação de novas gerações de pesquisadores, por meio das orientações de mestrados e doutorados e da institucionalização de núcleos de referência em suas instituições.
BERNARDETE A. GATTI, doutora em psicologia pela Universidade Paris VII, é coordenadora do Departamento de Pesquisa Educacionais da Fundação Carlos Chagas e professora do Programa de Pós-Graduação Psicologia da Educação, na Pontifícia Universidade Católica de São Paulo (PUC-SP). Publicou: Formação de professores e carreira: problemas e movimentos de renovação (Campinas: Autores Associados, 2003, $4^{\mathrm{a}}$ reimpressão); A construção da pesquisa em educação no Brasil (Brasília: Plano, 2004, 2a reimpressão); Estudos quantitativos em educação (Educação e Pesquisa - Revista da Faculdade de Educação da Universidade de São Paulo - USP, São Paulo, v. 30, nº 1, jan.-abr. 2004, p. 11-30); Reflexão sobre os desafios da pós-graduação: novas perspectivas sociais, conhecimento e poder (Revista Brasileira de Educação, Rio de Janeiro: ANPEd, Campinas: Autores Associados, nº 18, set.-dez. 2001, p. 108-116). Coordena a série Pesquisa em Educação, com nove livros publicados pela Editora Plano e o décimo, Grupo focal na pesquisa em ciências sociais e humanas, de sua autoria, foi agora publicado pela Líber Livro. Pesquisa em andamento: O papel da experiência e das práticas educacionais na constituição da profissionalidade do professor. E-mail: gatti@fcc.org.br

\section{Referências bibliográficas}

ANPEd-Associação Nacional de Pós-Graduação e Pesquisa, (1984). Documento sobre o Programa de Intercâmbio (datilografado). (1987). Proposta para o Programa de Intercâmbio (datilografado).

FCC - Fundação Carlos Chagas, (1981). Relatório da reunião sobre o Programa de Intercâmbio (datilografado).

Recebido em maio de 2005 Aprovado em junho de 2005 


\section{Resumos/Abstracts}

Bernardete A. Gatti

\section{Formação de grupos e redes de} intercâmbio em pesquisa educacional: dialogia e qualidade

Relata o processo de formação de grupos e rede de intercâmbio, apoiado pelo Conselho Nacional de Desenvolvimento Científico e Tecnológico (CNPq), Financiadora de Estudos e Projetos (FINEP), Instituto Nacional de Estudos e Pesquisas Educacionais Anísio Teixeira (INEP) e Coordenação de Aperfeiçoamento de Pessoal de Nível Superior (CAPES), nos anos de 1981 a 1992, com vista à melhoria da qualidade da pesquisa educacional no país, por meio do aperfeiçoamento dos profissionais envolvidos, da permuta de informações e da realização de trabalhos de pesquisa em cooperação, efetivado por uma rede sistemática de intercâmbio mediante o trabalho face a face por pesquisadores das várias instituições envolvidas, bem como pela assessoria a grupos emergentes por grupos mais solidamente estabelecidos na área. Analisa as conseqüências positivas desse processo, em particular como reforço a alguns grupos de trabalho da ANPEd.

Palavras-chave: pesquisa educacional; rede de intercâmbio; grupos de trabalho da ANPEd

Formation of groups and an exchange network in educational research: dialogue and quality
This article relates the process of formation of groups and an exchange network, supported by the CNPq, FINEP, INEP and CAPES in the period from 1981 to 1992 with the aim of improving the quality of educational research in the country. The goal was to offer further qualification to professionals involved in educational research by means of an exchange of information and by developing joint research based on a system of exchanges by means offace-to-face contact between the researchers involved. In addition, it offered consultancy to emerging groups delivered by those with a broad experience in the field. It analyses the positive consequences of this process and, in particular, how it helped to strengthen some of ANPEd's working groups.

Key-words: educational research; exchange network; working groups belonging to ANPEd 